\title{
THE OCCURRENCE OF DUTCH ELM DISEASE IN CANADA ${ }^{1}$
}

\author{
By A. W. McCallum \\ Forest Pathologist, Department of Agriculture, Ottawa
}

INTRODUCTION

$\mathrm{T}$

HIS destructive disease of elm was first observed in Holland shortly after the end of the first World War and within a few years it had spread over northwestern and central Europe. Its origin is unknown although there is a suggestion that it may have come from Asia where some elms are resistant to the causal fungus. In the United States the disease was first found at Cleveland and Cincinnati, Ohio, in 1930, and 1933 in New Jersey, Connecticut and New York. Since then it has spread and become well established in a considerable area in the vicinity of the City of New York. It has been clearly demonstrated that the causal fungus, together with the insects responsible for its distribution in Europe, were introduced into the United States on burl elm logs imported for making veneer.

\section{Occurrence and Distribution in Canada}

Since the advent of the disease in the United States it had been expected that ultimately it would appear in Canada, and measures were taken to ascertain its presence here as soon as possible after its introduction. However, although considerable work of this nature was done, it was not until late in the summer of 1944 that Dr. Rene Pomerleau of the Quebec Department of Lands and Forests collected specimens of diseased elm at St. Ours near Sorel in Richelieu County, which finally proved to be infected with the causal fungus of this disease. Subsequent scouting in that year indicated that the disease was present in nine localities in the vicinity of Lake St. Peter, an expansion of the St. Lawrence River about 50 miles below Montreal. The infected area was found to be about 40 miles in length and although only 28 infected trees were actually located it was believed that many more would be found when the region was examined by a much larger number of trained scouts during the following year.

In 1945 a programme of intensive scouting was carried out in Quebec upon a co-operative basis by the Dominion Department of Agriculture and the Quebec Department of Lands and Forests. In order to ascertain if the disease was present clsewhere than in Quebec a less detailed survey was made over a large part of southern. Ontario by the Dominion and Ontario Departments of Agriculture, and a limited amount of work was done in New Brunswick and Nova Scotia. The results of this work indicated that the disease was confined to Quebec but that it was widespread and well established there. In all a total of 1,321 infected trees were found from near the City of Quebec to Lachine and from Windsor Mills to St.

\footnotetext{
1 Contribution No. 861 from the Division of Botany and Plant Pathology, Science Service, Department of Agriculture, Ottawa
} 
Gabriel de Brandon, or in an area about 160 miles in length by about 90 miles at its maximum width. Judging from the large size of this area it was apparent that the disease had been present for a considerable period of time-possibly 10 years. The centre of the infection appeared to be Sorel but there is no definite evidence as to the manner in which the causal fungus was introduced, although the fact that Sorel is a seaport is suggestive. In view of the fact that the infected areas in the United States and in Canada are widely separated, the indications are that the disease came to Canada directly from Europe rather than from the United States.

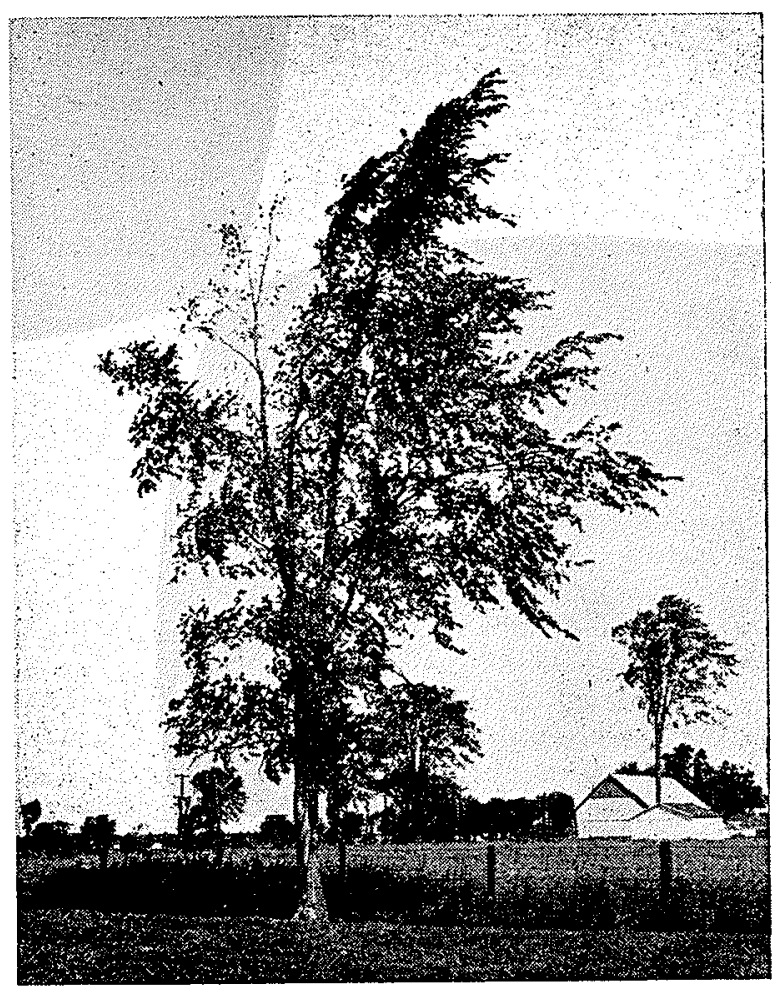

Fig. 1-Early stage of the disease.

SYMPTOMS

The first external symptom of this disease is a rapid wilting of the leaves in one or more limbs. The foliage on affected branches loses its colour, becomes shrivelled and brittle, and is usually shed prematurely (Fig. 1 and 2 ). If the affected tree is small it may all be involved at once. Often the tips of affected twigs assume a downward, hook-like curve which has been termed "shepherd's crook". When the leaves have fallen this is a diag. nostic aid. Wilting of the leaves usually appears first in mid-June and 
is most evident during July and August. Internally, diseased branches or stems in cross-section show a more or less continuous brown ring in the outer sapwood (Fig. 3). In longitudinal section the discolouration appears as long discontinuous streaks (Fig. 3). In the United States there is apparently considerable variation in the rate at which the disease affects the host and this may also hold for Canada, but observations made so far indicate that, in general, the disease progresses rapicily. There seems to be little evidence of a chronic condition in which the host gradually declines. On

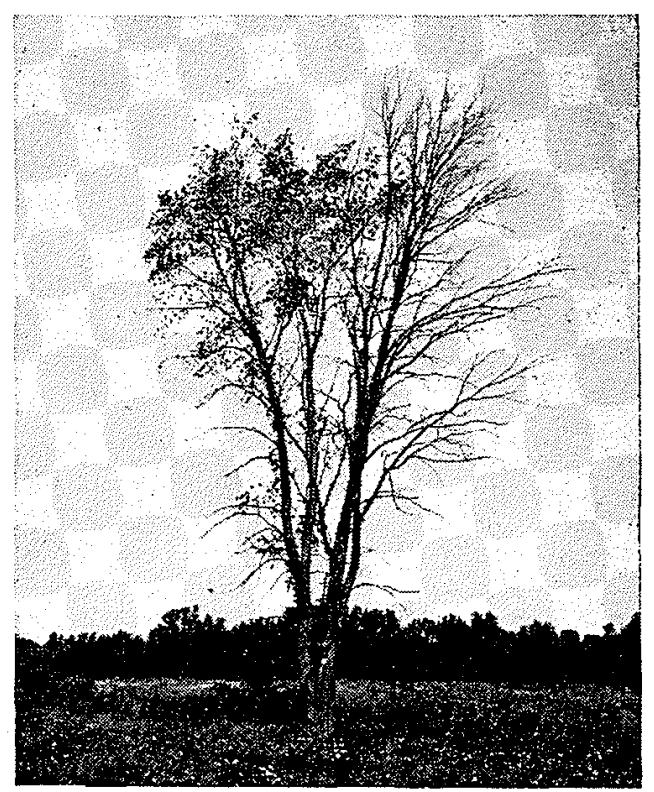

Fig. 2-Advanced stage of the disease.

the other hand, there is no doubt that many trees, both large and small, have been killed quickly by the disease (Fig. 4). The symptoms of Dutch elm disease, both internal and external, are so similar to those of two other native diseases of elm that identification in the field is not possible with certainty. The two indigenous diseases referred to are Verticillium wilt, caused by Verticillium albo-atrum R. and B. and V. dahliae Kleb., and Dothiorella wilt caused by Dothiorella ulmi Verrall and May. In view of the close similarity of gross symptoms, therefore, it is necessary to collect specimens of affected wood and to culture them in the laboratory. The cultural characteristics of the three fungi in question are sufficiently distinct to make identification comparatively simple.

\section{Cause}

Dutch elm disease is caused by a fungus which inhabits the sapwood. It was first known as Graphium ulmi Schwartz, but since then the perfect 
stage has been found in Europe and it is now called Ceratostomella ulmi (Schwartz) Buisman. In North America only the conidial or imperfect stage of the fungus has been found. The fungus develops in the vessels and is distributed within the tree by the movement of sap. Whether the wilting is caused by occlusion of the vessels or by a toxic effect upon them is uncertain. After the death of the host tissue the fungus continues to grow as a saprophyte, fruiting on exposed or covered surfaces of wood, on the inside of the bark, and in beetle tunnels. The fungus cannot be seen without the aid of a glass.

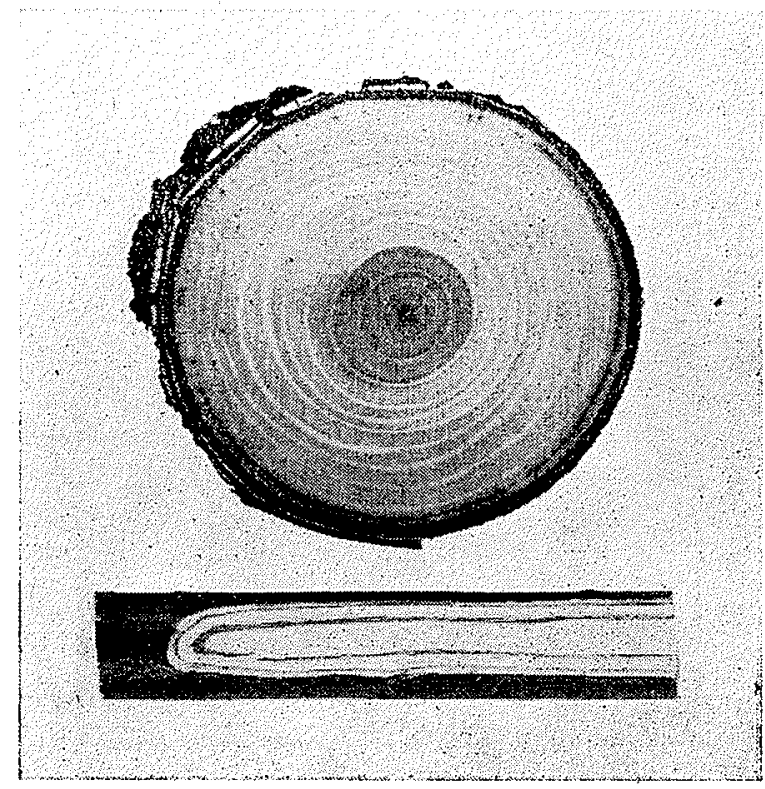

Fig. 3-Diseased elm wood in cross and longitudinal section showing the brown ring and streaks.

TRANSMISSION

The spores of Ceratostomella ulmi are sticky and so are not disseminated by air currents as is generally the case with fungus spores. Instead they are carried from diseased to healthy trees by bark beetles. In Europe the large and small European elm bark beetles, Scolytus scolytus Fab. and S. multistriatus Marsh. respectively, are the vectors of the causal fungus. Both these beetles have been introduced into the United States but only the latter appears to have become established. This beetle and the native elm bark beetle Hylurgopinus rufipes Eich. act as vectors in the United States. The former is said to be a very efficient carrier of the fungus. As far as is known at present this bark beetle does not occur in Canada. In Quebec only the native elm bark beetle has been found. This beetle is not supposed to be as effective a vector of the fungus as the European bark beetle, but 
in view of the widespread occurrence of the disease in Quebec this opinion seems to be open to question.

\section{IMPORTANCE OF ElMS}

There are three species of elm in Canada, viz. American elm, Ulmus

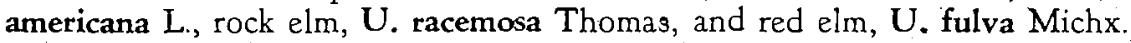
American elm occurs from Cape Breton Island to central Saskatchewan south of the Height of Land. Rock elm is confined to southern Quebec and Ontario and does not occur north of the Ottawa River or Georgian Bay. Red elm is found in the valley of the St. Lawrence as far west as

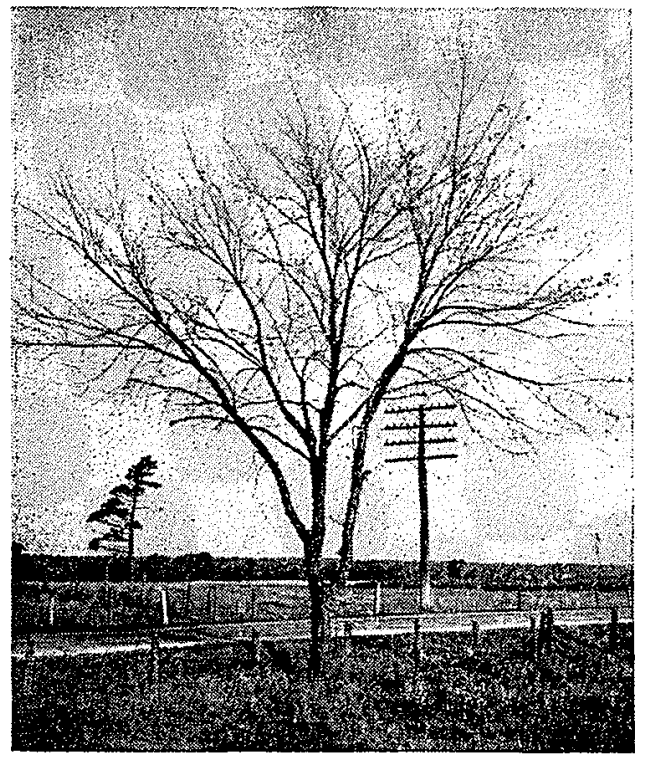

Fig. 4-Final stage of the disease.

the eastern end of Lake Superior. All three species are susceptible to Dutch elm disease. The most recent figures available show that elm ranks fifth among Canadian hardwoods in value of production. The wood is strong and tough and is used industrially for purposes which demand these qualities. It is used principally for slack cooperage, fruit baskets, crates, cheese boxes, low priced furniture, hubs of wagon wheels, ship-building, framework of heavy agricultural implements, flumes, axe handles, and hockey sticks. However, its considerable value in industry is far surpassed by its importance as an ornamental tree. This applies particularly to the American elm. On account of its rapid growth, pleasing form, and moderate shade, it has been used extensively for street planting in many eastern Canadian cities. As an individual ornamental in parks, private grounds, or on highways it is not excelled by any other native, broad-leaved species

(Fig. 5 and 6). It is the typical tree of the eastern Canadian landscape and 
any disease which threatens its existence immediately assumes the utmost significance.

\section{CONTROL}

When it first became known that Dutch elm disease was present in this country there was some hope that it might be eliminated, although the history of attempts to eradicate exotic diseases of trees in North America is not encouraging. However, as soon as the extent of the infected area became known, it was realizied that there was little or no likelihood of suppressing the disease entirely, and that the most that could be done would be to confine it to its present limits of distribution or at least to

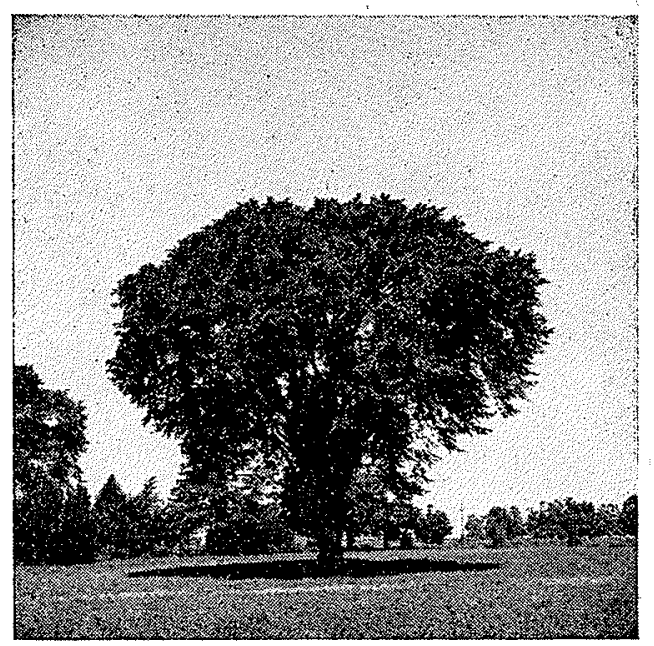

Fig. 5-An American elm in private grounds.

delay its spread to uninfected areas. In view of the fact that the causal fungus is carried from diseased to healthy trees entirely by bark beetles, the most effective method of control in an infected area is to reduce the beetle population. This involves the treatment of diseased trees, and all elm wood favourable for insect breeding, so as to render them unsuitable for the propagation of beetles. Infected trees must be felled, preferably early in spring to prevent emergence of beetles, and the wood destroyed or the bark removed and burned. The use of the wood of diseased trees as fuel is the most satisfactory method of disposal as this also eliminates the fungus, which persists as a saprophyte in dead wood. All other potential breeding material for beetles such as fallen trees, logs, firewood, and slabs should be treated or destroyed.

The felling of large trees, particularly in cities, towns, or villages, is a difficult and expensive operation and is only justifiable as a control measure when, as in the present instance, the host is a valuable species and there is a reasonable hope of preventing spread of the disease. Until the situation is further clarified in Quebec a policy of eradicating all known, diseased 
trees has been adopted. It may become necessary to modify this course but for the present it seems to be the most advisable action to take. A total of 1,349 infected trees have been found and practically all of these have now been cut down. Before the beginning of this field season the few remain. ing trees will have been eradicated.

During this year the known, infected area will be thoroughly examined again for new infections or for diseased trees which have escaped detection. Also, the country contiguous to the known, infected area, particularly to the south towards the United States and to the west towards Ontario, will be carefully scouted for evidence of outlying infections.

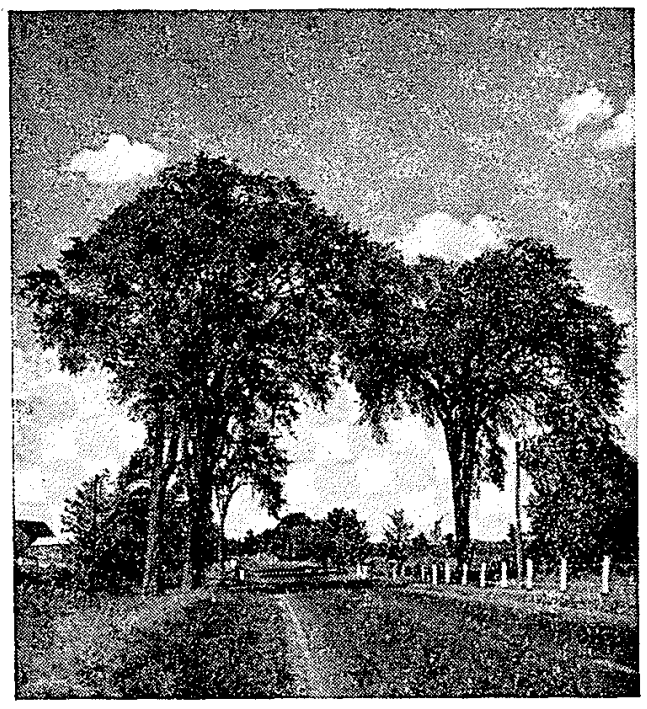

Fig.:6-American elms bordering an Ontario highway.

\section{ACKNOWLEDGEMENTS}

It is a pleasure at this time to acknowledge the invaluable assistance and advice which have been generously given by a number of officers of the United States Department of Agriculture in regard both to the field and laboratory phases of this problem. As a consequence much valuable time has been saved and maximum results have been obtained from the work done. The help which has been given is deeply appreciated.

\section{REFERENCES}

Boyce, J. S. Forest pathology. pp. 1-600. McGraw-Hill Book Co., Inc., New York. 1938.

May, C. Outbreaks of the Dutch elm disease in the United States. U.S. Dept. Agr. Circ. 322: 1-19. 1934.

Walter, J. 'M., C. May, and C. W. Collins. Dutch elm disease and its control. U.S. Dept. Agri. Circ. 677: 1.12. 1943. 